\title{
Burden, Type, and Associated Factors of Thyroid Dysfunction in Patients with Heart Failure in Sub-Saharan Africa: A Cross-Sectional Study
}

\author{
Liliane Mfeukeu-Kuate1,2, Honoré Kemnang Yemele1, Ahmadou Musa Jingi ${ }^{3 *}$, Martine Etoa ${ }^{2,4}$, \\ Jan Rene Nkeck1, Jerome Boombhi' ${ }^{15}$, Sylvie Ndongo Amougou ${ }^{1,6}$, \\ Chris Nadege Nganou-Gninjio ${ }^{1,2}$, Mesmin Yefou Dehayem1,2, Ama Moor Vicky ${ }^{1,6}$
}

\footnotetext{
${ }^{1}$ Faculty of Medicine and Biomedical Sciences, The University of Yaounde 1, Yaounde, Cameroun

${ }^{2}$ The Yaounde Central Hospital, Yaounde, Cameroun

${ }^{3}$ Faculty of Health Sciences, The University of Bamenda, Bamenda, Cameroon

${ }^{4}$ Faculty of Medicine and Pharmaceutical Sciences, The University of Douala, Douala, Cameroun

${ }^{5}$ The Yaounde General Hospital, Yaounde, Cameroon

${ }^{6}$ The Yaounde University Teaching Hospital, Yaounde, Cameroun

Email: mfeukeuliliane@yahoo.fr, kemyh937@gmail.com, ‘jingiahmadoumusa@yahoo.co.uk, claudetoa@yahoo.fr, jrnkeck@gmail.com, boombhijerome@yahoo.fr,ndongoamougou@yahoo.fr,cn_nganou@yahoo.fr, ydehayem@yahoo.com, movicky@gmail.com
}

How to cite this paper: Mfeukeu-Kuate, L., Yemele, H.K., Jingi, A.M., Etoa, M., Nkeck, J.R., Boombhi, J., Amougou, S.N., Nganou-Gninjio, C.N., Dehayem, M.Y. and Vicky, A.M. (2021) Burden, Type, and Associated Factors of Thyroid Dysfunction in Patients with Heart Failure in Sub-Saharan Africa: A Cross-Sectional Study. World Journal of Cardiovascular Diseases, 11, 485-497. https://doi.org/10.4236/wjcd.2021.1111046

Received: July 30, 2021

Accepted: November 13, 2021

Published: November 16, 2021

Copyright $\odot 2021$ by author(s) and Scientific Research Publishing Inc. This work is licensed under the Creative Commons Attribution International License (CC BY 4.0).

http://creativecommons.org/licenses/by/4.0/

(c) (i) Open Access

\begin{abstract}
Background: Various thyroid abnormalities have been reported during heart failure (HF). The present study aimed to evaluate the burden, type, and associated factors of thyroid disorders in Cameroonian patients with heart failure. Materials and Methods: We conducted a cross-sectional study from January to May 2020, involving volunteer adults followed for heart failure at the Yaoundé Central Hospital. Those receiving treatment that could cause thyroid dysfunction were excluded. Thyroid hormone levels (TSH, free T3, and free T4) were measured by enzyme-linked immunosorbent assay. Results: A total of 63 patients (30 women; $47.6 \%$ ) were included. The median age was 65 (IQR: 56 - 70) years. The main etiology of heart failure was hypertension (52.4\%) followed by valvular heart disease (14.3\%). Thyroid dysfunction was seen in 38 (60.3\%, [95\% CI: 47.2 - 72.4]) patients, of which 30 (79\%) had hypothyroidism and $8(21 \%)$ had hyperthyroidism. The most frequent thyroid dysfunction was Low T3 syndrome in 27\% (95\% CI: 16.6 - 39.7) of the study population followed sub-clinical hypothyroidism in 19.1\% (95\% CI: 10.3 30.9) of patients. Patients with HF and reduced ejection fraction (HFrEF) were more likely to have hypothyroidism than those with preserved ejection
\end{abstract}


fraction (OR: 3.5, [95\% CI: 1.2 - 9.9], $\mathrm{p}=0.016$ ). Also, patients with more than one hospital admission in the past 12 months were more likely to have hypothyroidism (OR: 5.3, [95\% CI: 1.3 - 21.5], p = 0.013). Conclusion: The burden of thyroid dysfunction was high in this group of patients with HF. These were mainly low T3 syndrome and sub-clinical hypothyroidism. These were associated with heart failure with reduced ejection fraction and those with more than one hospitalization within the past 12-months.

\section{Keywords}

Thyroid Dysfunction, Heart Failure, Sub-Saharan Africa

\section{Introduction}

Thyroid hormones play an important role in the homeostasis of the cardiovascular system in health and disease [1]. They influence the heart rate, myocardial contractility, diastolic function, and peripheral vascular resistance [1]. The positive inotropic and chronotropic effect of thyroid hormones can result in high output heart failure in the case of hyperthyroidism, while hypothyroidism is associated with atherogenicity thereby increasing the risk of ischemic heart disease and heart failure [2] [3]. Many studies in Caucasians have shown high rates of low T3 Syndrome characterized by low blood levels of free triiodothyronine (FT3) with normal levels of free thyroxine (FT4) and Thyroid Stimulating Hormone (TSH) [4] [5] [6]. This syndrome, initially considered to be an adaptive phenomenon, has deleterious effects in patients with heart failure (HF). It contributes to the worsening of cardiac function and is a strong predictor of mortality [1] [3] [4] [7]. Besides the low T3 Syndrome, other thyroid dysfunctions such as hyperthyroidism (clinical and sub-clinical) and hypothyroidism (clinical and sub-clinical) have been described in patients with chronic HF and are associated with poor prognosis [6] [7]. Due to the high burden and prognostic impact of thyroid dysfunction in patients with HF, the American Heart Association recommends the systematic assay of TSH [8].

Data on the burden of thyroid dysfunction and associated factors in patients with chronic HF are scarce in sub-Saharan Africa. This study aimed at describing the burden, type, and associated factors of thyroid dysfunction in patients with chronic heart HF in Cameroon, central Africa.

\section{Methods}

Study design and setting: We carried out a cross-sectional study between January and May 2020 in the Cardiology Unit of the Yaounde Central Hospital ( $\mathrm{YCH})$ of Cameroon. The $\mathrm{YCH}$ is a tertiary health institution that serves as one of the University teaching hospitals. The $\mathrm{YCH}$ has a catchment population of over 2 million inhabitants. 


\section{Study participants}

We included consenting patients of both sexes aged $\geq 21$ years with an established diagnosis of chronic HF (clinical and echocardiography) by a Cardiologist. We excluded those with a previous diagnosis of thyroid dysfunction, and those on medications that can alter the thyroid function such as; synthetic anti-thyroid, thyroid hormone supplements, amiodarone, corticosteroids, and nonsteroidal anti-inflammatory medications.

\section{Sample size}

We used the Cochran formula to estimate the sample size [9]. With a $10 \%$ precision and an estimated prevalence of $17.5 \%$ [10]. The minimal sample size was 56 participants.

\section{Data collection}

Data were collected using pre-established questionnaires. The following variables were collected in a face-to-face interview and complete physical examination: age, sex, duration of HF, number of hospitalizations within the past 12 months, NYHA functional class, the actual treatment of HF, resting blood pressure (using standard procedure), weight and height (to calculate the body mass index). We then collected venous blood after strict asepsis from a peripheral vein for the assay of thyroid hormones. TSH was measured using the ELISA Sandwich method and FT3 and FT4 were measured using the ELISA competition method. We also studied the patients' medical records to collect ECG and Echocardiographic data, as well as the type (preserved versus reduced ejection fraction) and the etiologic diagnosis of HF.

\section{Operational definitions}

We defined Euthyroidism as normal TSH (0.4 - $4.2 \mathrm{uIU} / \mathrm{ml})$, FT3, and FT4 (7 $22 \mathrm{pg} / \mathrm{ml}$ ). We defined Low T3 syndrome as FT3 $<2.2 \mathrm{pg} / \mathrm{ml}$ and normal TSH and FT4. We defined clinical Hyperthyroidism as TSH $<0.4 \mathrm{uIU} / \mathrm{ml}$ and FT4 $>$ $22 \mathrm{pg} / \mathrm{ml}$. Clinical hypothyroidism was defined as TSH $>4.2 \mathrm{uIU} / \mathrm{ml}$ and FT4 $<$ $7 \mathrm{pg} / \mathrm{ml}$. We defined sub-clinical hyperthyroidism as TSH $<0.4 \mathrm{uIU} / \mathrm{ml}$ and normal FT4. Sub-clinical hypothyroidism was defined as TSH $>4.2 \mathrm{uIU} / \mathrm{ml}$ and normal FT4 [11] [12] [13]. We defined heart failure with reduced ejection fraction when the left ventricular ejection fraction (echocardiography) at diagnosis was $<50 \%$ in a patient with heart failure syndrome.

\section{Statistical analyses}

Data were analyzed using Epi-Info version 7. Continuous variables are presented as medians (IQR) and discrete variables as proportions (95\% confidence intervals). We calculated the Odds ratios (OR) to assess the association between clinical and heart failure variables with thyroid dysfunction (Hyperthyroidism and hypothyroidism). A p-value $<0.05$ was considered statistically significant.

\section{Results}

\section{Characteristics of the study population}

We approached 96 patients with chronic HF of which 63-33 (52.4\%) males 
and $30(47.6 \%)$ females-were included in this study. The median age was 65 (IQR: 56 - 70) years. The clinical characteristics, HF characteristics, etiology, and treatment of HF are shown in Table 1. Most of the patients have had HF for more than 36 months (median duration of 36 months, [IQ: 5 - 66]), and about half had heart failure with reduced ejection fraction. The median ejection fraction was $43 \%$ (IQR: 30 - 81). The most frequent causes of HF were hypertensive (52.4\%) and valvular heart diseases (14.3\%). Diuretics (81\%) and beta-blockers (39.7\%) were the most frequently prescribed medications.

Table 1. Clinical, heart failure, and treatment characteristics of the study population.

\begin{tabular}{|c|c|c|c|}
\hline Variable & Overall, n(\%) & Male, $\mathrm{n}(\%)$ & Female, $\mathrm{n}(\%)$ \\
\hline \multicolumn{4}{|l|}{ Clinical data } \\
\hline Age $\geq 60$ years & $42(66.7)$ & $21(63.4)$ & $21(70)$ \\
\hline Obesity & $11(17.5)$ & $6(18.2)$ & $5(16.7)$ \\
\hline \multicolumn{4}{|l|}{ Heart Failure data } \\
\hline Duration of HF $\geq 36$ months & $34(54)$ & $23(69.7)$ & $11(36.7)$ \\
\hline Hospitalisations $>1$ in las 12 months & $14(22.2)$ & $7(21.2)$ & $7(23.3)$ \\
\hline $\begin{array}{l}\text { Heart Failure with Reduced Ejection } \\
\text { Fraction }\end{array}$ & $33(52.4)$ & $17(51.5)$ & $16(53.3)$ \\
\hline Global Heart Failure & $45(71.4)$ & $23(69.7)$ & $22(73.3)$ \\
\hline NYHA class 3 or 4 & $18(28.6)$ & $11(33.3)$ & $7(23.3)$ \\
\hline \multicolumn{4}{|l|}{ Etiology of HF } \\
\hline Hypertension Heart Disease & $33(52.4)$ & $19(57.6)$ & $14(46.7)$ \\
\hline Cardiomyopathies & $7(11.1)$ & $3(9.1)$ & $4(13.3)$ \\
\hline Arrhythmia Heart Disease & $7(11.1)$ & $4(12.1)$ & $3(10)$ \\
\hline Ischemic Heart Disease & $4(6.4)$ & $2(6.1)$ & $2(6.7)$ \\
\hline Valvular Heart Disease & $9(14.3)$ & $2(6.1)$ & $7(23.3)$ \\
\hline Congenital Heart Disease & $2(3.2)$ & $2(6.1)$ & 0 \\
\hline Toxic & $1(1.6)$ & $1(3)$ & 0 \\
\hline \multicolumn{4}{|l|}{ Treatment of Heart Failure } \\
\hline ACEI & $18(28.6)$ & $6(18.2)$ & $12(40)$ \\
\hline ARA2 & $9(14.3)$ & $4(12.1)$ & $5(16.7)$ \\
\hline Diuretics & $51(81)$ & $28(84.9)$ & $23(76.7)$ \\
\hline Digoxin & $12(19.1)$ & $6(18.2)$ & $6(20)$ \\
\hline Beta Blockers & $25(39.7)$ & $12(36.4)$ & $13(43.3)$ \\
\hline Calcium Channel Blockers & $12(19.1)$ & $8(24.2)$ & $4(13.3)$ \\
\hline Aspirine & $15(23.8)$ & $6(18.2)$ & $9(30)$ \\
\hline Heparin & $6(9.5)$ & $5(15.2)$ & $1(3.3)$ \\
\hline
\end{tabular}




\section{The burden of Thyroid dysfunction}

The median TSH was 1.4 (IQR: 1 - $2 \mathrm{uIU} / \mathrm{ml}$ ), FT3 was 2 (IQR: $1.2-3.1$ ), and FT4 was 12 (IQR: 7 - 15.2) pg/ml. The burden and type of thyroid dysfunction are shown in Table 2. Thyroid dysfunction was seen in 38 (60.3\%, [95\% CI: 47.2 72.4]) patients, of which 30 (79\%) had hypothyroidism and 8 (21\%) had hyperthyroidism. The most frequent thyroid dysfunction was Low T3 syndrome in $27 \%$ (95\% CI: 16.6 - 39.7) of the study population followed sub-clinical in $19.1 \%$ (95\% CI: 10.3 - 30.9) of patients.

\section{Factors associated with thyroid dysfunction:}

The factors associated with thyroid dysfunction are shown in Table 3. Patients with HF and reduced ejection fraction (HFrEF) were more likely to have hypothyroidism than those with preserved ejection fraction (OR: 3.5, [95\% CI: 1.2 9.9], $\mathrm{p}=0.016$ ). Also, patients with more than 1 hospital admission in the past 12 months were more likely to have hypothyroidism (OR: 5.3, [95\% CI: 1.3 21.5], $\mathrm{p}=0.013)$.

\section{Discussion}

Thyroid dysfunction is frequent in patients with chronic disease conditions including heart failure [14]. Amongst these functional disorders, low T3 syndrome is the most frequent in Caucasians [1] [7]. The pathophysiologic role is not well known, even though studies suggest an adaptive mechanism to minimize energy expenditure in patients with chronic diseases [15]. Nevertheless, based on the fundamental action of FT3 on the heart and vessels, a direct relationship between FT3 and poor prognosis in patients with chronic HF represents an interesting research pathway. It is postulated that the state of low FT3 can result in a hypothyroid-like syndrome which can contribute to or worsen intrinsic heart disease [15]. This work aimed at studying the burden and type of thyroid dysfunction in patients with chronic HF in an African context, as well as the associated factors. We found a high burden of thyroid dysfunction, especially low T3

Table 2. The burden of thyroid dysfunction in the study population.

\begin{tabular}{ccc}
\hline Variable & Frequency $(\mathrm{n})$ & $\%(95 \% \mathrm{CI})$ \\
\hline $\begin{array}{c}\text { Euthyroidism } \\
\text { Hyperthyroidism }\end{array}$ & 25 & $36.7(27.6-52.8)$ \\
Central & 1 & $1.6(0.04-8.5)$ \\
Primary & 1 & $1.6(0.04-8.5)$ \\
Sub-Clinical & 6 & $9.5(3.4-19.6)$ \\
Hypothyroidism & & $1.6(0.04-8.5)$ \\
Central & 1 & $19.1(10.3-30.9)$ \\
Sub-Clinical & 12 & $27(16.6-39.7)$ \\
Low T3 syndrome & 17 & \\
\hline
\end{tabular}


Table 3. Factors associated with thyroid dysfunction.

\begin{tabular}{|c|c|c|c|c|c|c|}
\hline \multirow{2}{*}{ Variable } & \multicolumn{3}{|c|}{ Hyperthyroidism $(\mathrm{n}=8)$} & \multicolumn{3}{|c|}{ Hypothyroidism $(\mathrm{n}=31)$} \\
\hline & Percentage & OR (95\%CI) & p-value & Percentage & OR $(95 \% \mathrm{CI})$ & $\mathrm{P}$-value \\
\hline \multicolumn{7}{|l|}{ Age $\geq 60$ years } \\
\hline Yes & 11.9 & $0.8(0.2-3.8)$ & 0.798 & 54.8 & $1.97(0.7-5.7)$ & 0.212 \\
\hline No & 14.3 & 1 & & 38.1 & 1 & \\
\hline \multicolumn{7}{|l|}{ Sex } \\
\hline Male & 15.2 & $1.6(0.4-7.4)$ & 0.540 & 45.5 & $0.7(0.3-1.56)$ & 0.532 \\
\hline Female & 10 & 1 & & 53.3 & 1 & \\
\hline \multicolumn{7}{|l|}{ Obesity } \\
\hline Yes & 9.1 & $0.6(0.1-5.8)$ & 0.692 & 45.5 & $0.8(0.2-3.1)$ & 0.784 \\
\hline No & 13.5 & 1 & & 50 & 1 & \\
\hline \multicolumn{7}{|l|}{ Duration of HF } \\
\hline$\geq 36$ months & 14.7 & $1.5(0.3-6.9)$ & 0.604 & 44.1 & $0.6(0.2-1.7)$ & 0.382 \\
\hline$<36$ months & 10.3 & 1 & & 55.2 & 1 & \\
\hline \multicolumn{7}{|c|}{ Hospitalization $>1 /$ year } \\
\hline Yes & 7.1 & $0.5(0.1-4.1)$ & 0.479 & 78.6 & $5.3(1.3-21.5)$ & 0.013 \\
\hline No & 14.3 & 1 & & 40.8 & 1 & \\
\hline \multicolumn{7}{|c|}{ Type of Heart Failure } \\
\hline HFrEF & 12.1 & $0.9(0.2-4)$ & 0.885 & 63.6 & $3.5(1.2-9.9)$ & 0.016 \\
\hline HFpEF & 13.3 & 1 & & 33.3 & 1 & \\
\hline \multicolumn{7}{|c|}{ Global Heart Failure } \\
\hline Yes & 13.3 & $1.2(0.2-6.8)$ & 0.811 & 48.9 & $0.96(0.3-2.9)$ & 0.937 \\
\hline No & 11.1 & 1 & & 50 & 1 & \\
\hline \multicolumn{7}{|c|}{ NYHA class 3 or 4} \\
\hline Yes & 5.6 & $0.3(0.04-2.8)$ & 0.282 & 55.6 & $1.43(0.5-4.3)$ & 0.524 \\
\hline No & 15.7 & 1 & & 46.7 & 1 & \\
\hline \multicolumn{7}{|l|}{ Hypertensive HF } \\
\hline Yes & 9.1 & $0.5(0.1-2.3)$ & 0.367 & 60.6 & $2.7(0.96-7.4)$ & 0.058 \\
\hline No & 16.7 & 1 & & 36.7 & 1 & \\
\hline \multicolumn{7}{|c|}{ Cardiomyopathy HF } \\
\hline Yes & 14.3 & $1.2(0.1-11.2)$ & 0.894 & 42.9 & $0.8(0.2-3.7)$ & 0.722 \\
\hline No & 12.5 & 1 & & 50 & 1 & \\
\hline \multicolumn{7}{|l|}{ Arrhythmia HF } \\
\hline Yes & 14.3 & $1.2(0.1-11.2)$ & 0.894 & 57.1 & $1.4(0.3-7)$ & 0.656 \\
\hline No & 12.5 & 1 & & 48.2 & 1 & \\
\hline
\end{tabular}




\section{Continued}

Ischemic Heart Disease

$\begin{array}{ccccccc}\text { Yes } & 25 & 2.5(0.2-27) & 0.445 & 50 & 1.03(0.1-7.8) & 0.974 \\ \text { No } & 11.9 & 1 & & 48.9 & 1 & \end{array}$

Valvular Heart Disease

$\begin{array}{ccccccc}\text { Yes } & 11.1 & 0.8(0.1-7.8) & 0.877 & 22 & 0.5(0.01-1.3) & 0.080 \\ \text { No } & 13 & 1 & & 53.7 & 1 & \\ \text { ACEI } & & & & & & \\ \text { Yes } & 5.6 & 0.5(0.04-2.8) & 0.282 & 44.4 & 0.8(0.3-2.3) & 0.633 \\ \text { No } & 15.6 & 1 & & 51.1 & 1 & \end{array}$

ARA2

$\begin{array}{ccccccc}\text { Yes } & 0 & \text { NA } & \text { NA } & 66.7 & 2.3(0.5-10.2) & 0.258 \\ \text { No } & 14.8 & 1 & & 46.3 & 1\end{array}$

Diuretics

$\begin{array}{ccccccc}\text { Yes } & 15.7 & \text { NA } & \text { NA } & 47.1 & 0.6(0.2-2.3) & 0.482 \\ \text { No } & 0 & 1 & & 58.3 & 1 & \end{array}$

Digoxin

$\begin{array}{ccccccc}\text { Yes } & 8.3 & 0.6(0.1-5.1) & 0.614 & 33.3 & 0.4(1-1.7) & 0.222 \\ \text { No } & 13.7 & 1 & & 52.9 & 1 & \end{array}$

Beta-Blockers

$\begin{array}{ccccccc}\text { Yes } & 4 & 0.2(0.02-1.6) & 0.093 & 56 & 1.6(0.6-4.3) & 0.382 \\ \text { No } & 18.2 & 1 & & 44.7 & 1 & \end{array}$

Calcium Channel Blocker

$\begin{array}{ccccccc}\text { Yes } & 8.3 & 0.6(0.1-5.1) & 0.614 & 66.7 & 2.4(0.7-9.1) & 0.179 \\ \text { No } & 13.7 & 1 & 45.1 & 1\end{array}$

Aspirine

$\begin{array}{lrccccc}\text { Yes } & 26.7 & 4(0.9-18.6) & 0.062 & 40 & 0.6(0.2-1.99) & 0.414 \\ \text { No } & 8.3 & 1 & & 52 & 1 & \end{array}$

Heparin

$\begin{array}{llccccc}\text { Yes } & 33.3 & 4.3(0.6-28.3) & 0.111 & 16.7 & 0.2(0.02-1.6) & 0.093 \\ \text { No } & 10.5 & 1 & 52.6 & 1\end{array}$

HF: Heart Failure; HFrEF: Heart Failure with reduced Ejection Fraction; HFpEF: Heart Failure with Preserved Ejection Fraction; NYHA: New York Heart Association; ACEI: Angiotensin-Converting Enzyme Inhibitors; ARA 2: Angiotensin Receptor Antagonist.

syndrome. This is similar to that reported in Caucasians and Asians [1] [6] [7]. This can be explained by the low peripheral conversion of FT4 to FT3 secondary to decreased expression of tissue 5' deiodinase [1] [5] [14]. Besides low T3 syndrome, 
other functional abnormalities have been observed such as hyperthyroidism (clinical and sub-clinical) and hypothyroidism (clinical and sub-clinical) [7]. These anomalies can occur before the occurrence of $\mathrm{HF}$, and could even be the cause of HF. Also, they can occur concomitantly after the occurrence of HF [7]. The high rate of these anomalies poses the problem of systematic evaluation of thyroid function in these patients. This systematic evaluation could be pertinent if correcting them will improve the prognosis. This is highly debatable in our setting where there is a lack of social security and the high costs of these tests and the non-demonstrated benefit of correction. Despite the potentially beneficial effects of supplementing thyroid hormones in patients with deficits, studies on the long-term benefits of supplementing thyroid hormones are few [1]. Morruzzi et al. demonstrated that administering L-Thyroxine orally to patients with idiopathic dilated cardiomyopathy significantly improved their physical performance, ejection fraction, and cardiac output in the short term [16]. Hamilton et al. demonstrated that perfusing FT3 in patients with class 3 and 4 HF and low FT3 significantly improves their cardiac output and reduction in systemic vascular resistance in patients taking high doses [17]. Malik et al. showed improvement of cardiac function after intravenous administration of FT4 in patients with severe systolic dysfunction and cardiogenic shock refractory to maximal doses of inotropes [18]. All studies have shown the short-term benefit of administering FT3 or FT4 in the acute setting [1]. To the best of our knowledge, there is no study on the long-term cardiovascular benefit of administering thyroid hormones to patients with HF [1]. Nevertheless, the use of FT3 in the studies so far showed good tolerance and no major side effects. One of the limitations of the existing studies is the use of short-acting FT3 preparations in patients with HF. To date, there are no sustained-release forms of thyroid hormones [1] [11] [13].

\section{Limitations and strength}

The cross-sectional design did not permit us to have an insight into the short and medium-term consequences of thyroid dysfunction on HF outcomes. Also, we were unable to tell the time at which thyroid dysfunction occurred as the median duration of evolution was 36 months. However, to the best of our knowledge, this is the first study of its kind in our setting. Further studies are needed with a cohort design to evaluate the prognostic significance of thyroid dysfunction in HF.

\section{Conclusion}

The burden of thyroid dysfunction was high in this group of patients with chronic HF in sub-Saharan Africa. These were mainly low T3 syndrome and sub-clinical hypothyroidism. These were associated with heart failure with reduced ejection fraction and those with more than one hospitalization within the past 12-months. Further studies are needed to assess the therapeutic implications of short-term and long-term supplementation of thyroid hormones in patients with chronic HF in a sub-Saharan setting. 


\section{Acknowledgments}

We thank the personnel of the Biochemistry laboratory of the Yaounde University Teaching Hospital and the Cardiology Unit of the $\mathrm{YCH}$. We also thank the participants for taking part in this study.

\section{Authors' Contribution}

Study design: Liliane MFEUKEU KUATE, Vicky AMA MOOR.

Data collection: Honoré KEMNANG YEMELE, Liliane MFEUKEU KUATE; Jerome BOOMBHI, Sylvie NDONGO AMOUGOU, Chis Nadege NGANOU.

Data analyses and interpretation: Honoré KEMNANG YEMELE; Vicky AMA MOOR, Jan René NKECK, Martine ETOA, and Ahmadou Musa JINGI, Mesmin Yefou DEHAYEM.

Draft of the manuscript: MFEUKEU KUATE, Honoré KEMNANG YEMELE, Jan René NKECK, Martine Liliane ETOA, Ahmadou Musa JINGI.

Critical appraisal: Jerome BOOMBHI, Sylvie NDONGO AMOUGOU, Chris Nadege NGANOU, Msmin Yefou DEHAYEM, Vicky AMA MOOR.

Supervision: Vicky AMA MOOR.

All the authors approved the final version for publication.

\section{Data Availability}

This will be made available on reasonable request.

\section{Ethical Statement}

This work was approved by the ethical committee of the Faculty of Medicine and Biomedical Sciences of the University of Yaounde 1. The YCH administration granted authorization. We carried out this work following the declarations of Helsinki. All patients gave signed consent for the study. We report this work following the STROBE Checklist.

\section{Conflicts of Interest}

The authors declare no conflicts of interest regarding the publication of this paper.

\section{References}

[1] Galli, E., Pingitore, A. and Iervasi, G. (2010) The Role of Thyroid Hormone in the Pathophysiology of Heart Failure: Clinical Evidence. Heart Failure Reviews, 15, 155-169. https://doi.org/10.1007/s10741-008-9126-6

[2] Biondi, B. (2012) Mechanisms in Endocrinology: Heart Failure and Thyroid Dysfunction. European Journal of Endocrinology, 167, 609-618. https://doi.org/10.1530/EJE-12-0627

[3] Danzi, S. and Klein, I. (2004) Thyroid Hormone and the Cardiovascular System. Minerva Endocrinology, 29, 139-150.

[4] Ascheim, D.D. and Hryniewicz, K. (2002) Thyroid Hormone Metabolism in Patients 
with Congestive Heart Failure: The Low Triiodothyronine State. Thyroid, 12, 511-515. https://doi.org/10.1089/105072502760143908

[5] Opasich, C., Pacini, F., Ambrosino, N., Riccardi, P.G., Febo, O., Ferrari, R., et al. (1996) Sick Euthyroid Syndrome in Patients with Moderate-to-Severe Chronic Heart Failure. European Heart Journal, 17, 1860-1866.

https://doi.org/10.1093/oxfordjournals.eurheartj.a014804

[6] Saurav, S., Singh, A., Debnath, A., et al. (2014) Prevalence of Low T3 Syndrome and Its Association with Severity in Patients of Chronic Heart Failure: A Hospital Based Study. Journal of the Association of Physicians of India.

[7] Kannan, L., Shaw, P.A., Morley, M.P., Brandimarto, J., Fang, J.C., Sweitzer, N.K., et al. (2018) Thyroid Dysfunction in Heart Failure and Cardiovascular Outcomes. Circulation: Heart Failure, 11, e005266. https://doi.org/10.1161/CIRCHEARTFAILURE.118.005266

[8] Hunt, S.A., Baker, D.W., Chin, M.H., Cinquegrani, M.P., Feldman, A.M., Francis, G.S., et al. (2001) ACC/AHA Guidelines for the Evaluation and Management of Chronic Heart Failure in the Adult: Executive Summary. A Report of the American College of Cardiology/American Heart Association Task Force on Practice Guidelines (Committee to Revise the 1995 Guidelines for the Evaluation and Management of Heart Failure). Journal of the American College of Cardiology, 38, 2101-2113. https://doi.org/10.1016/S0735-1097(01)01683-7

[9] Whitley, E. and Ball, J. (2020) Statistics Review 4: Sample Size Calculations. Critical Care, 6, 335-341. https://doi.org/10.1186/cc1521 https://ccforum.biomedcentral.com/articles/10.1186/cc1521

[10] Akono, M.N., Simo, L.P., Agbor, V.N., Njoyo, S.L. and Mbanya, D. (2019) The Spectrum of Heart Disease among Adults at the Bamenda Regional Hospital, Northwest Cameroon: A Semi-Urban Setting. BMC Research Notes, 12, Article No. 761. https://doi.org/10.1186/s13104-019-4803-1

[11] Thakur, C., Saikia, T.C. and Yadav, R.N. (1997) Total Serum Levels of Triiodothyronine (T3) Thyroxine (T4), and Thyrotropin (TSH) in School-Going Children of Dibrugarh District: An Endemic Goiter Region of Assam. Indian Journal of Physiology and Pharmacology, 41, 167-170.

[12] Sakamoto, S., Putalun, W., Vimolmangkang, S., Phoolcharoen, W., Shoyama, Y., Tanaka, H., et al. (2018) Enzyme-Linked Immunosorbent Assay for the Quantitative/Qualitative Analysis of Plant Secondary Metabolites. Journal of Natural Medicines, 72, 32-42. https://doi.org/10.1007/s11418-017-1144-Z

[13] Maes, M., Mommen, K., Hendrickx, D., et al. (1997) Components of Biological Variation, Including Seasonality, in Blood Concentrations of TSH, TT3, FT4, PRL, Cortisol, and Testosterone in Healthy Volunteers. In: Rees, A. and Druce, M., Eds., Clinical Endocrinology, John Wiley \& Sons Ltd., New York.

[14] Klein, I. and Danzi, S. (2007) Thyroid Disease and the Heart. Circulation, 116, 1725-1735. https://doi.org/10.1161/CIRCULATIONAHA.106.678326

[15] Giorgio, I., Alessandro, P., Patrizia, L., Mauro, R., Andrea, R., Maria, S., et al. (2003) Low-T3 Syndrome. Circulation, 107, 708-713. https://doi.org/10.1161/01.CIR.0000048124.64204.3F

[16] Moruzzi, P., Doria, E. and Agostoni, P.G. (1996) Medium-Term Effectiveness of L-Thyroxine Treatment in Idiopathic Dilated Cardiomyopathy. The American Journal of Medicine, 101, 461-467. https://doi.org/10.1016/S0002-9343(96)00281-1

[17] Neto, A.M. and Zantut-Wittmann, D.E. (2016) Abnormalities of Thyroid Hormone Metabolism during Systemic Illness: The Low T3 Syndrome in Different Clinical 
Settings. International Journal of Epidemiology, 2016, Article ID: 2157583.

https://doi.org/10.1155/2016/2157583

https://www.hindawi.com/journals/ije/2016/2157583/

[18] Malik, F.S., Mehra, M.R., Uber, P.A., Park, M.H., Scott, R.L. and Van Meter, C.H. (1999) Intravenous Thyroid Hormone Supplementation in Heart Failure with Cardiogenic Shock. Journal of Cardiac Failure, 5, 31-37. https://doi.org/10.1016/S1071-9164(99)90022-2

\section{Abbreviations}

HF: Heart Failure

TSH: Thyroid-Stimulating Hormone

FT3: Free Triiodothyronine

FT4: Free Thyroxine

ACEI: Angiotensin-Converting Enzyme Inhibitors

ARA2: Angiotensin Receptor Blocker

NYHA: New York Heart Association 


\section{Data Collection Sheet}

Patient ID number:

Survey Information:

1. ID:

2. Date of completion of the instrument:

Consent, Interview Language
3. Consent has been read and obtained:
1. YES
2. NO
4. Interview Language:
1. French
2. English
5. Contact phone number:

STEP 1: DEMOGRAPHIC INFORMATION (Please Circle the number preceding the right response.)
6. Sex:
1. Male
2. Female

7. Date of birth: day: month: year:

8. What is the highest level of education you have completed?
1. No formal schooling
2. Less than primary school
3. Primary school completed
4. Secondary school completed
5. High school completed
6. University completed

7. Postgraduate degree

9. What is your background?

Country:

If Cameroon, ethnic group:

10 . What is your marital status?
1. Never married
2. Currently married
3. Separated
4. Divorced
5. Widowed
6. Cohabiting

11. Which of the following best describes your main work status over the past 12 months?
1. Government employee
2. Private sector employee
3. Self-employed
4. Non-paid

STEP 2: Heart failure data

\begin{tabular}{|l|l|}
\hline 1. For how long have you been diagnosed with heart failure? & \\
\hline 2. Etiology of heart failure & \\
Hypertension: 1 & \\
Congenital heart disease: 2 & \\
Valve disease:3 & \\
Ischemic heart disease: 4 & \\
Cardiomyopathy:6 & \\
other: specify & \\
\hline 3. What is the current clinical stage according to the NYHA? & \\
\hline 4. Type of heart failure depending on the cavity & \\
Left heart failure: 1 & \\
Right heart failure: 2 & \\
Global heart failure :3 & \\
\hline 5. Number of hospitalization for heart failure during the last & \\
12 months & \\
\hline 6. What medications are you currently taking? & \\
\hline
\end{tabular}


STEP 3: History

\begin{tabular}{|l|l|l|}
\hline History & No $=0 ;$ Yes $=1$ \\
\cline { 2 - 3 } & Hyperthyroidism & \\
\hline Hypothyroidism & \\
\hline Diabetes & \\
\hline Hypertension & \\
\hline Chronic kidney disease & \\
\hline Dyslipidemia & \\
\hline Known or treated cancer & \\
\hline Chronic hepatopathy & \\
\hline HIV & \\
\hline Other: specify & \\
\hline Chronic alcoholism & \\
\hline smoking & \\
\hline
\end{tabular}

STEP 4: paraclinical Data

\begin{tabular}{|l|l|l|}
\hline Echocardiography & $\begin{array}{l}\text { Left ventricular systolic ejection } \\
\text { fraction (\%) } \\
\text { Simpson: } \\
\text { Teicholz: }\end{array}$ & $\begin{array}{l}\text { Yes=1, No=0 } \\
\text { Preserved: } \\
\text { Altered: } \\
\text { Mid-range: }\end{array}$ \\
\hline Electrocardiogram & Atrial fibrillation & Yes=1, No=0 \\
\hline Biological analysis & \multicolumn{2}{|l}{} \\
\hline Level of TSH(uUI/ml) & \\
\hline Level of $\mathrm{fT} 4(\mathrm{pg} / \mathrm{ml})$ & & \\
\hline Level of $\mathrm{fT} 31(\mathrm{pg} / \mathrm{ml})$ &
\end{tabular}

